\title{
3. Understanding the role of agricultural data on market power in the emerging Digital Agriculture sector: a critical analysis of the Bayer/Monsanto decision $^{1}$
}

\section{Can Atik}

\subsection{INTRODUCTION}

Although there might be a perception that agriculture is a rural activity that is far from technology, ${ }^{2}$ modern agricultural production has become densely data-driven with advanced Big Data implementations ${ }^{3}$ thanks to the proliferation of the Internet of Things (IoT) and cloud computing technologies. ${ }^{4}$ Agricultural data (ag-data) is collected via various methods and used in agricultural decision-making processes such as implementing sensors in fields to track and prevent crop diseases, using drones and satellite images to observe crop developments, or using IoT infrastructure in glasshouses to

1 This chapter has been presented at the 14th ASCOLA Conference on 27-29 June 2019 in Aix-en-Provence, France and subjected to double blind peer review. This research has been conducted with the support of the postgraduate scholarship program of the Ministry of National Education, Republic of Turkey.

2 See the ever-present perception that agriculture is even behind the industry, 'industrialization' or 'modernization' of agriculture theories after the 1980s, and the EU regulations' implicit adoption of these developments at Francis Synder, New Directions in European Community Law (1st edn., Weidenfeld and Nicolson, 1990), pp. 109-119.

3 Michael E. Sykuta, 'Big Data in Agriculture: Property Rights, Privacy and Competition in Ag Data Services' (2016) 19 International Food and Agribusiness Management Review 57, p. 58.

4 Harald Sundmaeker et al., 'Internet of Food and Farm 2020', in Ovidiu Vermesan and Peter Friess (eds), Digitising the Industry - Internet of Things Connecting the Physical, Digital and Virtual Worlds (River Publishers, 2016), pp. 132-133; Sjaak Wolfert et al., 'Big Data in Smart Farming - A Review' (2017) 153 Agriculture Systems, pp. 69-75. 
enhance coherence in management of the production. ${ }^{5}$ It is expected that Big Data will positively affect productivity, sustainability, food safety, efficiency of resources and waste management. ${ }^{6}$ Moreover, current developments are regarded as just the first step of a big revolution in the operation, management, and structure of the entire agricultural value chain. ${ }^{7}$

In line with these developments, the Digital Agriculture sector (the DAs) has emerged based on 'the collection of data and information about farms with the aim of providing tailored advice or aggregated data to farmers'. Within this particular sector, Agricultural Technology Providers (ATPs) ${ }^{9}$ offer various data-driven agronomic services for farmers to help them become better decision-makers from production to marketing stages of their profession. ${ }^{10}$ While Digital Agriculture practices create significant benefits, ${ }^{11}$ this data-driven transformation has brought about some competition law concerns. For instance, the European Commission (the Commission) reacted to the Bayer/Monsanto merger ${ }^{12}$ and implemented remedies ${ }^{13}$ due to inter alia the Digital Agriculture aspects of the concentration. ${ }^{14}$

Although there have been some attempts to discuss the case and the possible effects of Digital Agriculture on the agricultural inputs sector from a vertical integration perspective, ${ }^{15}$ the role of ag-data on providing services and on

5 Adam Lesser, 'Analyst Report: Big Data and Big Agriculture' (GIGAOM, 2014) https://gigaom.com/report/big-data-and-big-agriculture/ accessed 5 January 2021; Wolfert et al., n. 4, p. 73; Krijn J. Poppe et al., 'Information and Communication Technology as a Driver for Change in Agri-food Chains' (2013) 12 EuroChoices 60, pp. 60-63; Krijn J. Poppe et al., 'A European Perspective on the Economics of Big Data' (2015) 12 Farm Policy Journal 11, pp. 11-12.

6 Poppe et al., n. 5, p. 18.

7 Ibid., p. 12. Additionally, this development is not limited to food production, i.e. this may also have significant effects on various industries that are dependent on the agricultural raw material.

8 See the definition at Case No. COMP/M.8084 - Bayer/Monsanto, Commission Decision (29 May 2018), para 2442.

9 See at Sykuta, n. 3, p. 58, footnote 1.

10 Wolfert et al., n. 4, p. 74.

11 Poppe et al., n. 5, p. 11.

12 Which is the first investigation on the emerging Digital Agriculture sector so far. See at Bayer/Monsanto, n. 8, para 2555.

13 Ibid., para 3030 and the subsequent paras.

14 Ibid., para 2555.

15 Which predominantly focus on seeds/pesticides markets and reinforcement of concentration risks with Digital Agriculture implementations. See, for instance, Ioannis Lianos and Dmitry Katalevsky, 'Merger Activity in the Factors of Production Segments of the Food Value Chain - A Critical Assessment of the Bayer/Monsanto Merger' (2017) UCL-CLES Policy Paper Series: 2017/1; Maurice E. Stucke and Allen P. Grunes, 'An Updated Antitrust Review of the Bayer-Monsanto Merger' (2018) The 
market power of ATPs in the emerging DAs with a horizontal competition perspective has not been discussed enough so far. Therefore, this study aims to fill this gap in the literature by exploring data-driven market power in the DAs and also critically analyzing the Bayer/Monsanto decision in this regard. In particular, it will be argued that the Commission's considerations regarding the role of ag-data on market power might not be considered as comprehensive enough $^{16}$ since it did not provide an extensive analysis about distinguishing reasons for the emergence of data-driven market power in this new sector from the perspective of the economic characteristics of ag-data even though it touched upon various potential elements in the text such as network effects and first-mover advantage. ${ }^{17}$

As having a well-rounded understanding of data-driven dominance is of prime importance for possible future DAs cases, this chapter aims to identify (1) the sector dynamics and the ag-data's distinctive role on market power in the DAs; (2) the indispensable elements of an optimal market power assessment based on economic characteristics of ag-data in the sector; and (3) to what extent the Commission's considerations in the Bayer/Monsanto decision is compatible with them. In particular, this study puts forward that the most prominent element of data-driven entry barriers in the sector is switching costs stemming from legal and technical obstacles that prevent free-flow of data in the DAs. This is exacerbated by lack of data substitutability due to cross-dependency of farmers and ATPs in the data collection process. Even though these issues were mostly neglected in the decision, they should be taken into account during market power assessments in the possible future DAs cases.

The remainder of the chapter is organized as follows. Section 3.2 will convey the essential information regarding the Bayer/Monsanto decision to provide a baseline for the rest of the analysis. Section 3.3 will attempt to explore the economic characteristics of ag-data in order to generate an in-depth insight into the reasons for the emergence of data-driven market power in the DAs by also discussing the Commission's considerations in the Bayer/Monsanto decision.

Konkurrenz Group White Paper; Tom Verdonk, 'Planting the Seeds of Market Power: Digital Agriculture, Farmers' Autonomy, and the Role of Competition Policy', in Leonie Reins (ed.), Regulating New Technologies in Uncertain Times (Springer, 2019), pp. 112-115.

16 Maybe because it was the first case that separately evaluated the emerging DAs so far. See at Bayer/Monsanto, n. 8, para 2555. Although the Commission touched upon precision farming in the Dow/DuPont decision (See at Case No. COMP/M.7932 - Dow/DuPont, Commission Decision (27 March 2017), para 246), the DAs was not under the investigation in this case.

17 Bayer/Monsanto, n. 8, paras 2830-2846. 
Section 3.4 will provide an overall evaluation regarding the Commission's data-driven market power assessment in the Bayer/Monsanto decision, and it will put forward some suggestions for future cases. In light of this, Section 3.5 will conclude by formulating an optimal market power test for the DAs.

\subsection{BAYER/MONSANTO MERGER CASE}

There has been a merger wave amongst the agricultural giants within the last decade. In 2013, Monsanto acquired The Climate Corporation mainly because of its data sets by paying nearly USD 1 billion. ${ }^{18}$ After this data-driven takeover in the US, Monsanto attempted to acquire Syngenta in July 2014, but this attempt was not successful due to the rejection from the target company. ${ }^{19}$ However, these activities started a broader merger trend, including mega-mergers such as ChemChina/Syngenta, ${ }^{20}$ Dow/DuPont,${ }^{21}$ and finally Bayer/Monsanto. ${ }^{22}$ This merger wave mainly decreased the number of market players in the agricultural inputs sector, but the DAs was also affected because nearly all the merging conglomerates had Digital Agriculture operations as well. ${ }^{23}$ However, the Commission provided a standalone investigation about Digital Agriculture related concerns only in the last one, the Bayer/Monsanto merger. ${ }^{24}$

\subsubsection{Bayer/Monsanto Case at a Glance}

According to the Commission, the transaction would create the largest globally integrated seed and pesticide player, and this would have significant impacts on price and innovation in several markets, including seeds, pesticides, and also Digital Agriculture. ${ }^{25}$ In particular, the concern was that this merger

18 Tony Danova, 'Big Data Is Worth \$1 Billion To Agricultural Giant Monsanto' (Business Insider, 2013) https://www.businessinsider.com/monsanto-buys-climate -corporation-for-1-billion-2013-10?international=true\&r=US\&IR=T accessed 5 January 2021.

19 Lianos and Katalevsky, n. 15, p. 2.

20 Case No. COMP/M.7962 - ChemChina/Syngenta, Commission Decision (5 April 2017).

21 See Dow/DuPont, n. 16 above.

22 See Bayer/Monsanto, n. 8 above.

23 Lianos and Katalevsky, n. 15, p. 3, footnote 7.

24 See at Bayer/Monsanto, n. 8, para 2555.

25 'Mergers: Commission clears Bayer's acquisition of Monsanto, subject to conditions' (2018) https://ec.europa.eu/commission/presscorner/detail/en/IP_18_2282 accessed 5 January 2021 ['Press release' henceforth]. 
'would have strengthened Monsanto's dominant position on certain markets, where Bayer is an important challenger of Monsanto'. ${ }^{26}$

The Commission's investigation identified particular competition concerns about Digital Agriculture. ${ }^{27}$ It focused on the loss of potential competition in Europe between Bayer's recently launched Xarvio and Monsanto's FieldView platform, the leading platform worldwide, which was about to be launched in Europe. ${ }^{28}$ As a response to this, Bayer offered a set of commitments ${ }^{29}$ to license a copy of its worldwide current offering and pipeline on Digital Agriculture to BASF (The BASF Divestment Package) ${ }^{30}$ in order to maintain competition by allowing BASF to replicate Bayer's position in the European Economic Area (EEA) ${ }^{31}$ However, after this initial commitment, Bayer requested to replace its original commitment with complete divestment of its Digital Agriculture assets and products to BASF with a condition of a temporary license back to these assets and products on 11 April 2018, and the Commission approved this by considering it was sufficient to maintain the race to become a leading supplier in Europe in this emerging field. ${ }^{32}$

\subsubsection{The Commission's Relevant Market Definition and the Broader Digital Agriculture Sector}

Services that ATPs provide for farmers are divergent, and there are various markets in the DAs. Some companies offer services in pest and disease modelling, some focus on satellite data, others have weed monitoring services with cameras, or there are crop modelling and nitrogen optimization services, and some ATPs have image recognition services for disease identification. ${ }^{33}$ Markets may also vary according to input types such as herbicides, insecticides, fungicides, fertilizers, plant growth regulators or seeds. ${ }^{34}$ Additionally, markets may be further distinguished according to crop groupings such as broadacre crops, e.g. corn, wheat, or barley. ${ }^{35}$ While being aware of this market

\footnotetext{
26 Ibid.

27 Inter alia the Commission's particular concerns in (a) seeds and traits, (b) pesticides, and (c) other initial concerns that were not confirmed during the investigation such as innovation in biological pesticides and bee health. See more at ibid.

28 Ibid.

29 Other commitments were about (a) vegetable seeds, (b) broadacre seeds and traits, and (c) pesticides. See more at ibid.

30 See more detail at Bayer/Monsanto, n. 8, para 3046 and subsequent paras.

31 Press release, n. 25 above.

32 Ibid.

33 See more at Bayer/Monsanto, n. 8, Annex - 3, p. 44.

34 Ibid., para 2576.

35 Ibid., paras 2577-2578.
} 
variety, the Commission's concerns focused on the market 'for the provision of digitally-enabled prescriptions of fungicides for broad acre crops in the EEA $^{\prime 36}$ in the Bayer/Monsanto merger.

The crucial point of discussion in the market definition part is related to whether the provision of digitally-enabled prescriptions can be considered under the same market with traditional agronomic advisory services, as the Notifying Party (Bayer) argues that they are in the same broader market. ${ }^{37}$ However, the Commission rejected this argument by considering demand and supply sides of the related services that differentiate these two markets significantly because the demand requires much more detailed and customized services whereas supply is much more complicated, which requires significantly different capabilities such as accessing huge data sets and having advanced algorithms, compared to traditional agronomic advisory services. ${ }^{38}$

Regarding the relevant geographic market, the Commission stated that it was determined as 'national' 39 by considering several elements such as language differences, different farming practices, government regulations, types of crops, local crop diseases and farmers' ATP preferences that have regional focuses. ${ }^{40}$

As this study mainly focuses on market power, there will not be a substantial discussion about market definition, but it is necessary to state that the approach of the Commission on market definition appears reasonable. ${ }^{41}$ The Commission is aware of the divergent services for farmers in the DAs. It identified the sector in general as well as the particular relevant and geographic markets in detail. However, it is difficult to argue that the data-driven market power assessment in the Bayer/Monsanto decision is as comprehensive as in the relevant market considerations to identify the most delicate parts of the matter.

\footnotetext{
Ibid., para 2612.

Ibid., paras 2557-2561.

Ibid., paras 2562-2578.

Ibid., paras 2583 and 2593.

Ibid., paras 2583-2592.
}

Indeed, there is a trend that attaches less importance to market definition, and more significance to theories of harm and identification of anticompetitive strategies in data-driven markets investigations. See Jacques Crémer, Yves-Alexandre de Montjoye and Heike Schweitzer, 'Competition Policy for the digital era - Final Report' (Publications Office of the European Union, 2020), pp. 3-4 ['EU Report', henceforth]. On the other hand, it is important to note that some competitors had concerns regarding other Digital Agriculture markets as well. See at Bayer/Monsanto, n. 8, para 2598. 


\subsubsection{Competitive Assessment: Digital Agriculture Aspects of the Concentration}

Within the competitive assessment part, the Commission starts with the concerns raised during the market investigation. According to the questionnaires conducted by the Commission with stakeholders, it was highlighted that the merger would result in higher prices, narrower choices and less innovation in the sector. ${ }^{42}$ In particular, competitors were worried about the acceleration of network effects and possible predatory pricing strategies in the post-merger period by bundling agricultural inputs and Digital Agriculture services. ${ }^{43}$ The risk of increased entry barriers for small-scale start-ups was also underlined by arguing that the new company would control too many IP rights and data. ${ }^{44}$ These risks drove competitors to a general concern about the dominance of the merged entity in Europe that would influence all the rival services. ${ }^{45}$

The Notifying Party argued that the merging parties were not leaders in the sector and their existing Digital Agriculture activities were related to different stages of the agricultural process, and thus, they did not overlap each other as Monsanto did not provide services in the EEA, and no evidence showed it would enter in a timely manner. ${ }^{46}$ Additionally, the Notifying Party asserted that merging parties' access to data was not unique and the combination of data sets via the merger would not give them a competitive advantage, ${ }^{47}$ and there was no basis for first-mover advantage or network effects concerns. ${ }^{48}$ Also, it put forward that there were enough competitive constraints by rivals in the sector, there was no plan to cease innovation activities in the post-merger period, market investigation of the Commission was misleading, and the market was not defined based on widely accepted market studies. ${ }^{49}$

However, the Commission rejected these arguments by listing and comparing the existing and upcoming products of the merging entities, and discussing Monsanto's capabilities, strategic position, plans and possible entry to the EEA. ${ }^{50}$ Based on this comparison, it concentrated on the elimination of

Bayer/Monsanto, n. 8 , para 2594.
Ibid., para 2599.
Ibid., para 2600.
Ibid., para 2601 .
Ibid., paras 2602-2606.
Ibid., para 2603. This study strongly opposes this allegation as the substitutability of ag-data can be very limited or not possible in some situations. See more discussion in Section 3.3.2.6.

48 Bayer/Monsanto, n. 8, para 2609.

49 Ibid., paras 2607-2611.

$50 \quad$ Ibid., paras 2614-2699. 
potential competition ${ }^{51}$ by considering that the merging parties had significant strengths and capabilities that constituted significant competitive constraints to each other. ${ }^{52}$ Eventually, the Commission concluded that the transaction was likely to lead a significant impediment to effective competition due to the elimination of an important competitive constraint in the post-transaction period. ${ }^{53}$

The Commission could not obtain reliable data about market shares of the merged entities as the sector is new and still emerging. ${ }^{54}$ Therefore, the competitive assessment was conducted based on the following main layers of substantial analysis.

In the first layer, in addition to the existing and upcoming products comparison as the indication of potential competition, ${ }^{55}$ the Commission considered the rivals' internal reports and their views along with the internal documents of merging parties to demonstrate that they might have imposed important competitive constraints to each other in the absence of the transaction. ${ }^{56}$ For instance, the view of BASF was stressed in the decision in a way that Monsanto was the leading player in Digital Agriculture globally, and Bayer was also the leading player in the EEA. ${ }^{57}$ Accordingly, the Commission also concluded that Monsanto was the leader in the sector globally and likely to become the leader in the EEA, and Bayer was 'ahead of the other competitors with regard to digitally-enabled prescriptions of crop protection products in the EEA' ${ }^{58}$

In order to support the conclusion declared in the first layer, the Commission provided additional reasons. The first reason was that the merging parties' superior knowledge about their conventional seeds and pesticides businesses could generate competitive advantage in the post-merger period. ${ }^{59}$ Second, as access to raw data is one of the fundamental pillars in digitally-enabled prescription services, merging parties' data collection networks would help them to generate better prescriptions thanks to their superior access to the public, third-party, customer and proprietary data sets. ${ }^{60}$ The text provided the merging parties' data access capabilities such as their data collection partner-

$51 \quad$ Ibid., para 2612, and subsequent paras. In particular, para 2631.

52 Ibid., para 2700.

53 Ibid., para 2872. As will be discussed below, although there are accurate considerations in this analysis, there are also significant missing points or potentially misleading evaluations for future DAs cases, if not this one. See more discussion in Section 3.3.2.

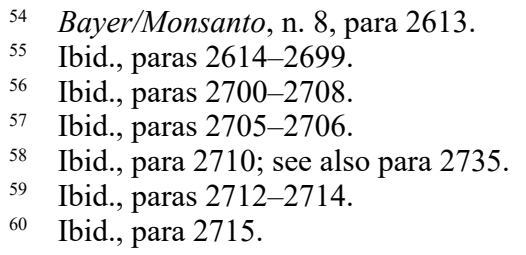


ships with third parties including John Deere, AGCO and others in addition to their farm data sets ${ }^{61}$ from their customers, and also in-house research and proprietary data about their input products. ${ }^{62}$ After listing the related capabilities, the Commission again referred to rivals' opinions regarding the combination of these data sets. For instance, it was indicated that data aggregation in the hands of the merged entity might generate clear advantages compared to rivals ${ }^{63}$ with better algorithms trained through these superior data sets, or a wide variety of data could enable Bayer/Monsanto to expand their services to other crop types and services. ${ }^{64}$ This was summarized as the ability to offer services and improve them as well as to develop new services compared to rivals. ${ }^{65}$ The third factor was the merging players' powerful agronomic engines and data processing capacities. ${ }^{66}$ Therefore, the Commission considered that the creation of prescriptions by combined capabilities and data sets of the merging giants would be superior compared to products of those who have relatively limited access to these required data layers. ${ }^{67}$ Thus, the decision refused the Notifying Party's arguments about not having unique access on proprietary (about seeds and pesticides) and third-party data sets, and the absence of any competitive superiority over rivals. ${ }^{68}$ It concluded that the distinctive capabilities of the merging companies generate a competitive advantage, and the merger would eliminate close potential competition as well as significant competitive constraints in the market. ${ }^{69}$

This study agrees with the related considerations to a large extent. However, the Commission did not provide a standalone analysis regarding the replicability or substitutability of these data sets ${ }^{70}$ even though this is one of the most important parameters when assessing how concerning a data combination could be from the competition point of view. ${ }^{71}$ Additionally, the conclusions

${ }^{61}$ However, the text did not discuss details, importance or the distinctive role of farm data in the sector.

62 See Bayer/Monsanto, n. 8, paras 2720-2723.

63 However, there is not any discussion about how serious this concentration would be, what the separate roles of these data sets on market power are, whether they are replicable or not.

${ }_{64}$ Bayer/Monsanto, n. 8, para 2726.

65 Ibid., para 2727. See detailed discussion in Section 3.3.2 below.

66 See Bayer/Monsanto, n. 8, paras 2729-2734. However, data's importance on providing prescription services was still stressed as the decisive one. See para 2733.

67 Ibid., para 2734.

68 Ibid., para 2728.

69 Ibid., paras 2734 and 2738.

70 Especially, it underestimated the farm data component throughout the analysis.

71 See the importance of determining replicability/substitutability of data when assessing data-driven market power at EU Report, n. 41, pp. 49 and 101-105; see also 
were mostly supported by rivals' opinions, but depending too much on competitors' concerns might not be considered as the optimal analytical criteria to understand the role of ag-data on market power in the DAs. Instead, the Commission could have provided more detailed economic characteristics analysis based on the sector realities and the facts of the particular case. ${ }^{72}$

The third assessment layer in the decision focused on the existing competitors of the merging parties. The Commission concluded that very few players (such as DowDupont, ChemChina/Syngenta or BASF) ${ }^{73}$ might have comparable capabilities, but even they could not exercise a sufficient degree of competitive pressure on the merged entity in the post-merger period based on its investigation conducted with questionnaires, conference calls and also direct interactions in a trade fair. ${ }^{74}$ The reason behind this conclusion is strictly related to data-driven prescription services' dependency on a wide variety of data. ${ }^{75}$ In particular, the Commission underlined the importance of proprietary data $^{76}$ on agricultural inputs and capacity of data processing tools, ${ }^{77}$ and emphasized the difficulty to reach an equal capability with the merging entity for rivals ${ }^{78}$ by also considering that the non-integrated companies such as small start-ups or software developers did not have the required genetic and performance insight about inputs in terms of scale and/or scope to provide digitally enabled prescriptions equal with integrated giants. ${ }^{79}$ The Commission also

Autorité de la concurrence and Bundeskartellamt, 'Competition Law and Data' (2016), pp. 44-47 ['Franko-German Report' henceforth].

72 The fourth assessment layer touched upon some of them, but the critical ones were neglected. See Section 3.3.2 for a more detailed discussion in this regard.

73 Bayer/Monsanto, n. 8, para 2758. However, it concluded that they were unlikely to exercise competitive pressure in the post-merger period effectively. When evaluating the other integrated giants' possible competitive constraints such as DowDupont, ChemChina-Syngenta or BASF, the Commission, concluded that they were either not active in the EEA or did not have the comparable capabilities for the particular market under investigation. See more at paras 2787-2829. Moreover, even though they had enjoyed the equal capabilities to compete, they would have faced the first-mover advantage of the merging entity and eventual network effects. See paras 2817 and 2826.

74 Ibid., paras 2739-2744; see also paras 2827-2829.

75 Ibid., para 2746.

76 The decision focused too much on proprietary data sets (data about seed or pesticide performance). See at ibid., paras 2470 and 2745-2829. The Commission's assessment is correct but does not represent the whole picture in the sector as data-driven market power is not limited to proprietary data sets. See more discussion in Section 3.3.2.1 below.

77 Bayer/Monsanto, n. 8, para 2747.

78 Ibid., para 2748.

79 Ibid., para 2750 - see also para 2760; for software companies, there is an additional limitation regarding farmers' data as they are further away from farmers compared to integrated inputs giants such as merging parties. See paras 2782-2786. 
checked the large distributors and agricultural equipment companies, but concluded that the former ones had the same limitations with the small start-ups in terms of the required capabilities. ${ }^{80}$ Even though the latter ones have certain services in the broader DAs, machine producers are collaborators rather than competitors in the data-driven prescription services. ${ }^{81}$ Exclusive access to proprietary data sets, for sure, is a highly relevant parameter to assess the effect of data accumulation on the market power of merging parties, especially in the inputs (seed and pesticide) prescription markets as in the case of the merger. However, it can be argued that the Commission overfocused on the proprietary data advantage, and neglected the role of farmers' data and the distinctive nature of the users (farmers) and ATPs' relationships on market power. ${ }^{82}$

In the fourth layer of the assessment, the Commission mentioned the first-mover advantage and network effects as the main characteristics of the DAs (including the specific market under investigation) and argued that these were likely to decrease potential post-merger competitive constraints further. ${ }^{83}$ The Commission reached this conclusion by investigating merging parties' internal documents, ${ }^{84}$ but did not provide a detailed explanation about the reasons for this conclusion. It particularly referred to an internal document containing Bayer's positive feedback loop expectations, i.e. the more subscribers (farmers) in the Digital Agriculture services means more authentic products, which in turn attracts more farmers as additional users of the services. ${ }^{85}$ The Commission connected positive feedback loops with the first-mover advantage by stating that first-comers could create a quality advantage compared to late-comers, and this might constitute entry barriers as the users would not have any incentive to switch new services ${ }^{86}$ by again referring to internal documents of Bayer and Monsanto about the importance of quantity and quality of farmers' data to develop better services. ${ }^{87}$

$80 \quad$ Ibid., paras 2763-2768.

81 Ibid., paras 2769-2779.

82 The Commission mentioned the importance of accessing farmers' data to compete in the market in general. Ibid., paras 2783 and 2786. However, it did not discuss farm data's relevance to market power assessments in the sector in detail. See extensive discussion on the matter in Section 3.3.2.

83 Bayer/Monsanto, n. 8, para 2830.

84 Ibid., para 2831.

85 Ibid., para 2836.

86 Ibid., para 2837.

87 Ibid., paras 2838-2840. However, these natural user preferences might not be the correct base of the theory of harm for the decision. This paper argues that focusing on data related lock-ins might have been a more solid approach when considering the sector conditions. See below Section 3.3.2 in general, and especially Section 3.3.2.9. 
Understanding the economic characteristics of ag-data is the most delicate part of the market power assessment, but the Commission frequently used internal documents or rivals' opinions in its discussion instead of providing an in-depth analysis about the sector conditions from the perspective of the economic characteristics. Additionally, the Commission's very brief assessment in this layer reflects only a part of the story. ${ }^{88}$ The next sections will provide a comprehensive analysis regarding the role of ag-data on market power in the DAs. In particular, the chapter will demonstrate that even though the first-mover advantage is the most prominent characteristic of the DAs, the reason behind this advantage is more related to switching costs, which mainly derive from farmers' data related to lock-in situations due to legal and technical barriers that prevent free data flow in the sector. This already high switching cost is exacerbated by the lack of substitutability of farm data because of the distinctive cross-dependency of farmers and ATPs in the costly data collection process.

The last layer of the substantive assessment in the decision is about whether Bayer will continue the same innovation efforts in Digital Agriculture in the post-merger period. Based on the market investigation and the internal documents of the merging parties, the Commission concluded that the pre-merger separate innovation efforts were unlikely to be continued as they would be merged in the post-merger period. ${ }^{89}$

As a general consideration, even though the concerns and large parts of the reached conclusions are not far from the sector realities, it can be argued that especially the data-driven market power considerations could have been much more analytical based on generating insights from a comprehensive economic characteristics discussion instead of overreliance on stakeholder ideas as discussed in detail below.

88 For instance, the Commission used quotes from individual calls with KWS and DowDupont about switching costs and network effects in order to complement its main position on the importance of the first-mover advantage and network effects, but the Commission did not provide a separate switching costs analysis. However, especially KWS's statements on switching costs contain very crucial hints about the most delicate parts of the data-driven entry barriers in the DAs that were not covered deservedly by the Bayer/Monsanto decision; 'It is difficult to switch from one platform to another, since the industry is not able to agree on one common data protocol (joint data format), therefore there is high incentive for the farmer to decide on only one platform. Even though farmers keep the ownership of provided data and they can contractually request that their data are returned to them, from the technical point of view, such data are not compatible with another platform and can therefore not be easily transferred to another platform from a practical point of view.' See at ibid., paras 2742-2843.

89 Ibid., paras 2847-2862. 


\subsection{EXPLORING DATA-DRIVEN MARKET POWER IN THE DIGITAL AGRICULTURE SECTOR}

\subsubsection{The Concept of Market Power}

The market power ${ }^{90}$ of a company is a highly significant parameter of competition law analysis for all kinds of cases because it may lead to detrimental consequences that contradict the main aim of the EU competition law, i.e. consumer welfare..$^{91}$ Accordingly, the Commission's guidelines on the assessment of horizontal mergers ${ }^{92}$ consider creation or strengthening of a dominant position via mergers as a primary form of such competitive harm. ${ }^{93}$

In the conventional market power assessment, the first determinant is the market shares of the merging undertakings. ${ }^{94}$ It is considered that very large market shares -50 percent or more ${ }^{95}$ - might be a significant indicator of dominance although there might be exceptional circumstances, and the importance

90 The level of market power that leads to dominance is described in the United Brands $v$ Commission case as 'a position of economic strength enjoyed by an undertaking, which enables it to prevent effective competition being maintained on a relevant market, by affording it the power to behave to an appreciable extent independently of its competitors, its customers and ultimately of consumers'. Case T-27/76 United Brands Company and United Brands Continental v Commission ECLI:EU:C:1978:22, para 65.

91 Richard Whish and David Bailey, Competition Law (Oxford University Press, 2018), p. 25; see some other risks and potential sufferers from data-driven dominance at Wolf Sauter, 'A Duty of Care to Prevent Online Exploitation of Consumers? Digital Dominance and Special Responsibility in EU Competition Law' (2019) Journal of Antitrust Enforcement, pp. 11-13.

92 Guidelines on the assessment of horizontal mergers under the Council Regulation on the control of concentrations between undertakings, OJ C 31, 5.2.2004 ['Horizontal Merger Guidelines', henceforth].

93 Ibid., para 2. Dominance "provides an important indication as to the standard of competitive harm that is applicable when determining whether a concentration is likely to impede effective competition to a significant degree'. See para 4.

94 Market shares provide a useful first indication for the Commission regarding the market structure and the relative importance of the various undertakings active on the relevant market. See at Case 85/76 Hoffmann-La Roche \& Co. v Commission [1979] ECLI:EU:C:1979:36, paras 39-41; Case C-62/86 AKZO v Commission [1991] ECLI:EU:C:1991:286, para 60; Case T-30/89 Hilti v Commission [1991] ECLI:EU:T: 1991:70, paras 90, 91 and 92; Case T-340/03 France Télécom v Commission [2007] ECLI:EU:T:2007:22, para 100. Basically, it is calculated based on the ratio of sales of a company compared to the total sales in the market. See more at the EU Report, n. 41, p. 48.

95 Horizontal Merger Guidelines, n. 92, para 17; AKZO v Commission, n. 94, para 60; Case T-221/95, Endemol v Commission, [1999] ECLI:EU:T:1999:85, para 134, and Case T-102/96, Gencor v Commission, [1999] ECLI:EU:T:1999:65, para 205. 
of the market shares might vary from market to market. ${ }^{96}$ However, with the datafication of the economy, these exceptional situations have become more frequent because conventional assessment tools struggle to perform their function. ${ }^{97}$ Especially in dynamic and fast-growing markets with short innovation cycles, market shares might not represent the market power correctly. ${ }^{98}$ In such cases, entry barriers in the relevant markets are stated as helpful to assess the market power more accurately. ${ }^{99}$

Although one may consider that services are not provided free of charge in the DAs ${ }^{100}$ and, thus, the market shares might represent the market power to a certain extent, ${ }^{101}$ focusing solely on market shares might still be deceptive in such a highly dynamic and still emerging data-driven sector. Also, this dynamism might not be limited to the infancy period of the sector as there is no constant stability regarding the roles and powers of players due to the everlasting innovative developments, i.e. market players' positions are changing in line with IoT and Big Data advancements. ${ }^{102}$ Ongoing adoption of Smart Farming practices by farmers might also influence this instability. Indeed, estimations for the EEA-wide revenues were not stable at the time of the transaction in the Bayer/Monsanto decision. ${ }^{103}$ Accordingly and accurately, the Commission did not focus on market shares in Bayer/Monsanto by saying that there was

96 See Hoffman-La Roche, n. 94, para 41.

97 Especially in data-driven online markets. See at Rupprecht Podszun and Stephan Kreifels, 'Data and Competition Law', in Vanessa Mak, Eric Tjong Tjin Tai, and Anna Berlee (eds), Research Handbook in Data Science and Law (Edward Elgar Publishing, 2018), p. 191.

${ }_{98}$ Case T-79/12 Cisco Systems Inc. and Messagenet SpA v Commission, [2013] ECLI:EU:T:2013:635, para 69. Digital platforms are considered as one of the prominent examples of this, i.e. lack of market shares' effectiveness in market power assessment. See EU Report, n. 41, pp. 48-50; See, for instance, the Commission's consideration at Case No. COMP/M.7217 - Facebook/WhatsApp, Commission Decision (3 October 2014), para 99. See more at Inge Graef, 'Market Definition and Market Power in Data: The Case of Online Platforms' (2015) 38 World Competition: Law and Economics Review 473, p. 503.

99 Especially, in the substantial assessment of data-driven mergers. See EU Report, n. 41 , p. 116.

100 See generally at Sundmaeker et al., n. 4; See Bayer's business model, for instance, at Bayer/Monsanto, n. 8, para 2547; See also the FieldView as an example at 'Pricing' (FieldView, 2018) https://climate.com/pricing accessed 10 February 2020. See more information about the business model of the sector in Section 3.3.2.5 below.

101 If the market shares can be calculated properly.

102 Wolfert et al., n. 4, p. 75; Sundmaeker et al., n. 4, p. 147.

103 Bayer/Monsanto, n. 8, para 2448; Even though the Commission did not investigate Digital Agriculture in the Dow/DuPont decision, it touched upon the issue when explaining industry trends and new technology developments as it is still unclear which player will emerge as a leader in this area'. See at Dow/DuPont, n. 16, para 246. 
no reliable data about market shares. ${ }^{104}$ Moreover, it can be argued that even though there had been reliable data about market shares, this might still have been misleading to solely depend on as they may represent only a part of the broader picture because of the determinative role of data on the market power of ATPs beyond the ratio of sales of a company compared to the total sales in a market, as explained in detail below.

However, market shares can be useful when calculated with an innovative approach. For instance, the German competition authority, Bundeskartellamt, assessed the market shares based on the number of users in the platform compared to the total users in the relevant market in its Facebook decision. ${ }^{105}$ However, this method might not fit in well with the market shares assessment in the DAs because the number of users might not directly represent the data advantage or market shares of ATPs as one ATP might have more data-driven advantage/income with fewer users compared to their rivals if the subscriber farms conduct large-scale activities, and thus, upload more data and pay more subscription fees. Therefore, focusing on the number of acres for which an ATP is providing services compared to the total acres in the relevant market might be a more useful criterion to identify. ${ }^{106}$

On the other hand, as farmers have a profoundly weak position against ATPs, ${ }^{107}$ which have standard 'take it or leave it' terms and conditions that are closed to negotiations, ${ }^{108}$ farmers have very limited power to decide on already collected data sets, and they are highly dependent on ATPs and machine producers. ${ }^{109}$ Therefore, countervailing buyer power might have much less meaning when investigating the market power of a company in the DAs compared to market shares. For this reason, the main focus should be on entry barriers when exploring data-driven market power.

104 Bayer/Monsanto, n. 8, para 2613.

105 See Case Summary of Facebook decision, B6-22/16, p. 6 https://www .bundeskartellamt.de/SharedDocs/Entscheidung/EN/Fallberichte/Missbrauchsaufsicht/ 2019/B6-22-16.pdf?_blob=publicationFile\&v=4 accessed 5 January 2021.

106 Of course, this has to be complemented with a broader data-driven market power assessment by focusing on entry barriers due to explained dynamism in the sector.

107 Sundmaeker et al., n. 4, p. 144; Verdonk, n. 15, pp. 118-119; Mihalis Kritikos, 'Precision Agriculture in Europe - Legal, Social and Ethical Considerations' (EPRS | European Parliamentary Research Service, 2017), p. 39.

108 See more in Section 3.3.2.1.

109 See more in Sections 3.3.2.1 to 3.3.2.6. 


\subsubsection{Assessing Data-driven Entry Barriers in the Digital Agriculture Sector}

\subsubsection{Switching costs}

There are significant reasons that make switching from one ATP to another highly difficult or costly for farmers. The question of 'can farmers take the historical data with them if they move to another supplier?" 110 is critical in this regard. As KWS (one of the stakeholders that the Commission had individual calls with) hinted, ${ }^{111}$ there are two main reasons for data-driven lock-in concerns in the DAs, i.e. legal ambiguity in data rights and technical barriers to transfer data. To understand the reasons for this, it is vital to know first, what the ag-data covers, and what the legal status of its main proportion is.

\section{Agricultural data}

The notion of agricultural data or agronomic data covers different types of data sets that are relevant for the Digital Agriculture services. It can be analyzed from two different perspectives: (1) its collection sources and function, as well as (2) its legal status. ${ }^{112}$

1. Types of ag-data according to collection sources - There are three main data types in the DAs according to their sources and function: ${ }^{113}$ (1) farm data (collected from farms via sensors, machines or directly by farmers for tailor-made agronomic prescriptions); (2) complementary data (such as weather, satellite and other environmental data, including precipitation events, evapotranspiration, and heat unit accumulation): ${ }^{114}$ and (3) proprietary data (such as data of an agricultural inputs company about its agronomic products, the results of the field tests and other exclusive information) ${ }^{115}$ In order to provide farmers with Digital Agriculture services,

110 See EIP-AGRI 'Data Revolution: Emerging New Data Driven Business Models in the Agri-Food Sector' https://ec.europa.eu/eip/agriculture/sites/agri-eip/files/eip -agri_seminar_data_revolution_final_report_2016_en.pdf accessed 5 January 2021, p. 12 ['EIP-A GRI report', henceforth].

111 Bayer/Monsanto, n. 8, para 2842, table 170. However, the Commission did not discuss this issue apart from citing the view of KWS.

112 Although the decision explored the importance of agricultural data sets, it neglected their legal status.

113 Bayer/Monsanto, n. 8, para 2453.

114 Keith Coble et al., Advancing U.S. Agricultural Competitiveness with Big Data and Agricultural Economic Market Information, Analysis, and Research (FARE, 2016), p. 3. See also another type of categorization at the same source.

115 See Bayer/Monsanto, n. 8, para 2453. 
different combinations of these data sets might be needed according to the type of services. ${ }^{116}$

2. Applicable legal regime to ag-data - In its decision, the Commission did not discuss the legal status of ag-data or any possible legal regime applicable to it even though this may substantially affect the competitive assessment. ${ }^{117}$ In particular, it is critical to know whether the collected ag-data can be considered as personal or non-personal. This categorization is essential to determine data control and portability (or existence of any) regime in the DAs.

As 'farm data' is more related to the mentioned lock-in problem of farmers compared to the other two components of the broader notion of ag-data, it deserves particular attention. The so-called 'farm data' is further categorized in the literature, namely (a) process-mediated data; ${ }^{118}$ (b) machine-generated data; ${ }^{119}$ as well as (c) human-sourced data, ${ }^{120}$ and the main proportion of data in the sector is considered as machine-generated non-personal data. ${ }^{21}$ Additionally, the complementary data and proprietary data might not represent personal characteristics as they are related to the environment and performance of agricultural inputs which might not easily be associated with a natural person. Indeed, paragraph 9 of the Regulation on a framework for the free-flow of non-personal data in the European Union gives ag-data as an example of non-personal data. ${ }^{122}$

116 Ibid., paras 2453 and 2724.

117 Regardless of its reason, i.e. whether it was a conscious choice or negligence, it has to be noted that this is a problematic silence because, for instance, determining whether there is an explicit right to data portability for the related data sets might affect the data substitutability assessment, which is also absent in the Commission's analysis to a large extent, as discussed in detail at below Section 3.3.2.6.

118 Which covers purchasing inputs, feeding, seeding, applying fertilizer, taking an order, etc. See at Wolfert et al., n. 4, p.74.

119 Which is generated by IoT systems such as sensors and smart machines. See ibid.

120 It is based on human experiences, which have been recorded in books and works of art, and later in photographs, audio and video. This data is generally not well structured and stored. Therefore, in Big Data related discussions, human-sourced data is rarely mentioned except marketing part of the agricultural value chain. See at ibid.

121 Ibid. See also Kritikos, n. 107, p. 15; See EU Report, n. 41 above, p. 87. This gives soil data as an example of 'strictly non-personal' data; See also Podszun and Kreifels, n. 97, p. 193.

122 '... Specific examples of non-personal data include ... data on precision farming that can help to monitor and optimise the use of pesticides and water.' See Regulation (EU) 2018/1807 of the European Parliament and of the Council of 14 November 2018 on a framework for the free flow of non-personal data in the European Union, OJ L 303, 28.11.2018, pp. 59-68 ['Free flow of non-personal data regulation', henceforth]. 
On the other hand, even if these data sets are considered as personal, the applicability of the General Data Protection Regulation (GDPR) ${ }^{123}$ framework might not be effective enough in the sector. It must be recalled that the only beneficiaries of data protection rules under the GDPR are natural persons. ${ }^{124}$ Therefore, farms, which are run by legal persons (both small- and medium-sized enterprises (SMEs) and corporations), cannot institutionally benefit from the GDPR framework. Here, one may think that workers of these farms might enforce their rights as natural persons, but this can be highly burdensome and confusing as workers are not a part of the contractual relationship with ATPs, and it might be highly complicated to determine which worker collects which data. Also, enforcement would fail if the related workers leave the job.

Moreover, the free-flow of non-personal data regulation does not provide any binding data portability right ${ }^{125}$ for non-personal data sets. It only suggests the creation of sector-specific voluntary codes of conduct. ${ }^{126}$ Indeed, the joint EU Code of Conduct on agricultural data sharing was released by a coalition of the EU agri-food associations on 23 April 2018 in Brussels. ${ }^{127}$ However, although this is a noteworthy endeavor to mitigate legal ambiguities in the sector, it is not a binding regulation. ${ }^{128}$ It is rather a guideline, which might be voluntarily followed by the stakeholders in the sector. Additionally, the superiority of contractual freedom prevails despite the proposed rules: 'unless otherwise agreed in the contract, the data originator (farmer) has the right to transmit this data to another data user'. ${ }^{129}$ The same emphasis of 'unless stated in the contract' is repeated when discussing the portability of data. ${ }^{130}$ Considering farmers' weaker position vis-à-vis ATPs while they are entering into agreements, ${ }^{131}$ it

123 Regulation (EU) No. 2016/679 of the European Parliament and of the Council of 27 April 2016 on the protection of natural persons with regard to the processing of personal data and on the free movement of such data ('GDPR') [2016] OJ L 119/1.

124 See Article 1 of the GDPR.

125 Which lets the right holders transfer their data sets from one company to another.

126 Free flow of non-personal data regulation, n. 122, Article 6.

127 See more at 'EU Code of conduct on agricultural data sharing by contractual agreement' (Copa and Cogeca et al., 2018) https://www.cema-agri.org/ images/publications/brochures/EU_Code_of_conduct_on_agricultural_data_sharing by_contractual_agreement_update_2019.pdf accessed 5 January 2021 ['EU Code of Conduct', henceforth].

128 Ibid., p. 4.

129 Ibid., p. 9.

130 Ibid., pp. 9-10.

131 Sundmaeker et al., n. 4, p. 144; Verdonk, n. 15, pp. 118-119; Kritikos, n. 107, p. 39 . 
can be argued that the EU Code of Conduct does not present a helpful approach for the data lock-in problem, especially from the enforcement and functionality perspective. ${ }^{132}$

Data-driven lock-ins in the Digital Agriculture sector due to legal ambiguity Connected to the explained legal ambiguity, one of the most prominent discussions in the literature is whether data belongs to farmers, data collectors (if not farmers), ATPs, landowners or even financial lenders. ${ }^{133}$ This uncertainty makes farmers concerned as they might not have discretion about the data collected from their farms. ${ }^{134}$ This concern was also mentioned in the EIP-AGRI workshop in 2016 that ambiguity of data ownership and lock-in situations might detrimentally affect the development of the sector. ${ }^{135}$

Even though some ATPs try to relieve farmers' concerns by stating 'yes, you own the data' in their discourse, their terms and conditions generally contain ultimate rights in favor of ATPs. ${ }^{136}$ For instance, some ATPs restrict the usage of the collected 'farm data' in another field of the same farmer if there is no contractual relationship for this second field. ${ }^{137}$ Similarly, usage of farm data (collected by, for instance, ATP 1) by another service provider (for instance, ATP 2) is sometimes prohibited by the terms and conditions after the contractual relationship ends with the ATP $1 .{ }^{138}$ As a more robust and relevant

132 See more detailed discussion at Can Atik and Bertin Martens, 'Competition Problems and Governance of Non-personal Agricultural Machine Data: Comparing Voluntary Initiatives in the US and EU' (Joint Research Centre of the European Commission | Digital Economy Working Paper 2020-07-JRC121337, Seville 2020) https://ec.europa.eu/jrc/sites/jrcsh/files/jrc121337.pdf accessed 5 January 2021.

133 Coble et al., n. 114, p. 6; See also Joan K. Archer and Cordero A. Delgadillo, 'Key Data Ownership, Privacy and Protection Issues and Strategies for the International Precision Agriculture Industry' (2016) Proceedings of the 13th International Conference on Precision Agriculture, p. 3.

134 Sundmaeker et al., n. 4, p. 144; Leanne Wiseman, Jay Sanderson and Lachlan Robb, 'Rethinking Ag Data Ownership' (2018) 15 Farm Policy Journal 71, pp. 71-72.

135 See EIP-AGRI report, n. 110, p. 14.

136 Kritikos, n. 107, p. 17; See also Monty Guild and Tony Danaher, 'Big Data Comes to the Farm' (Financial Sense, 2014) https://www.financialsense.com/ contributors/guild/big-data-farm accessed 5 January 2021; Matt McIntosh, 'Data Ownership Questions - and Why They're Important' (Future Farming, 2018) https:// www.futurefarming.com/Tools-data/Articles/2018/10/Data-ownership-questions-and-why-theyre-important-340743E/ accessed 5 January 2021; Jop Esmeijer et al., 'Data-driven Innovation in Agriculture: Case Study for the OECD KBC2-Programme' (2015) TNO report R10154, p. 27.

137 Sykuta, n. 3, pp. 68-69.

138 Ibid. 
example for this study, Monsanto's FieldView platform ${ }^{139}$ makes a clear distinction between personal and non-personal data in its terms and conditions. ${ }^{140}$ For personal data, it provides a separate set of terms and conditions that contains a list of what is considered as personal data. ${ }^{141}$ Related provisions on non-personal farm data start by saying that farmers and farms own the data, but the rest of the text shows that the data can only be shared with other FieldView users or platform partners of FieldView, not with rivals. ${ }^{142}$ There is no portability provision outside of the platform. Moreover, the terms and conditions state that both hardware and software are licensed, not sold. ${ }^{143}$ The hardware includes the FieldView Drive, the hard disk that collects and stores all data. ${ }^{144}$ Since there is no undisputed and explicit data portability right for farmers, it is difficult to see how farmers could transfer their data to another platform when they desire to do so.

Apart from ATPs' ultimate power on the collected data, there are similar concerns in the agricultural machinery side because agricultural machinery and vehicles also have data collection tools. ${ }^{145}$ It is stated that multinational machinery giants apply end-user license agreements (EULA) regarding the usage of machinery and data collection procedure (in which farmers have minimal access after collection), and in these agreements, there are particular provisions to let machine producers block the machines if farmers do not abide by the data collection guidelines in the scope of EULA. ${ }^{146}$ For instance, John Deere goes beyond and claims that they do not sell the tractors. Instead, it claims that farmers only get 'an implied license for the life of the vehicle to operate the vehicle' when they pay for the tractor. ${ }^{147}$ By saying that, Deere can also claim that the data (generated by the tractor) is also owned by Deere based

139 The core concern in the Bayer/Monsanto merger was the concentration of this platform's capabilities with Bayer's Xarvio. See Section 3.2.1 above.

140 'Climate Fieldview ${ }^{\mathrm{TM}}$ Terms of Service' (Climate.com, 2020) https://climate .com/fieldview-terms-of-service accessed 5 January 2021.

141 Ibid., para 1.2 - Personal Data.

142 Ibid., para 4, in particular, para 4.3 - Sharing Data with other Climate FieldView Users and Platform Partners.

143 Ibid., para 1.5 - Limited License.

144 Ibid., para 3.1 - Lease of Equipment.

145 EIP-AGRI report, n. 110, p. 10.

146 See, for instance, John Deere's practices at 'Vendor Lock-in, DRM, and Crappy EULAs Are Turning America's Independent Farmers into Tenant Farmers' (boingboing.net, 2018) https://boingboing.net/2018/03/08/you-are-the-product-5.html accessed 5 January 2021.

147 Kyle Wiens, 'We Can't Let John Deere Destroy the Very Idea of Ownership' (Wired.com, 2015) https://www.wired.com/2015/04/dmca-ownership-john-deere/ accessed 5 January 2021. 
on the law of property principles. ${ }^{148}$ Additionally, agricultural vehicles are highly expensive, and inherently constitute very high fixed costs for farmers. This alone has the potential to lock farmers in existing machine providers during the time for paying debts of the agricultural machinery ${ }^{149}$ and even maybe after the financial burden due to the need for technological support and maintenance. If the data dependency is added on top of that, it is highly difficult to speak about farmers' freedom of choice. This might speculatively mean that farmers might become only tractor drivers for agricultural machinery producers to collect ag-data in the scope of the 'Smart Farming' practices.

\section{Technical challenges in interoperability and standardization}

In addition to the legal uncertainty, there are also technical barriers regarding the adaptability of one infrastructure to another system requirement. ${ }^{150}$ It is argued that hardware/software systems are sometimes intentionally designed to block moving data to rival systems in order to nudge farmers to buy the whole system from the same company. ${ }^{151}$ There are very limited data standards as a result of this so-called 'brand protection' strategy, and therefore, technical interoperability barriers prevent further innovation and technological advancement due to lack of interconnection of farming equipment and tools. ${ }^{152}$ Sundmaeker and others assert that this proprietary architecture in technical compatibility of systems and lack of data standards are the core reasons for the absence of widespread interoperability. ${ }^{153}$ Accordingly, Lianos and Katalevsky argue that lack of interoperability might bring about farming solution clusters where services cannot be changed with other companies' services, and this can be detrimental for existing and potential competition as well as innovation in the sector. ${ }^{154}$ To put it another way, interoperability and standards are critical for farmers to ensure their autonomy to choose the best services from the wide range of alternatives for each particular need in the farm instead of depending on one integrated bundle of services from a single company. ${ }^{155}$

148 In the scope of the right to the fruits (fructus) element of ownership right.

149 Kritikos, n. 107, p. 7.

150 Sundmaeker et al., n. 4, pp. 142-143; See also at Esmeijer et al., n. 136, pp. 24-25; Copa-Cogeca /European Farmers European Agri-Cooperatives, 'Main Principles Underpinning the Collection, Use and Exchange of Agricultural Data', QJ(16)2689:6 - DA/FG/mvs, p. 3 ['Copa-Cogeca', henceforth].

151 Guild and Danaher, n. 136; Kritikos, n. 107, p. 19.

152 Kritikos, n. 107, p. 19. See also at EIP-AGRI report, n. 110, p. 14.

153 Sundmaeker et al., n. 4, p. 143.

154 Lianos and Katalevsky, n. 15, p. 1.

155 To give an example, farmers should be legally and technically able to use their soil data collected through a soil analysis company in order to get seeding prescription services from another company that also needs soil data sets to provide services. This 
As a general consideration, switching costs in the sector have a distinctive and strong role in creating entry barriers when considering legal and technical reasons together. Furthermore, by taking into account farmers' weaker position vis-à-vis ATPs in behaving autonomously (they cannot negotiate on or change standard terms and conditions, ${ }^{156}$ to be more precise) and highly imbalanced contractual provisions regarding the control of collected data, ${ }^{157}$ already explained high switching costs render the first-mover ATPs ultimate decision-makers on third parties' access to data regardless of the wills of farmers. This, in turn, could make them the gatekeepers of the DAs beyond locked-in data sets' significant competitive advantage for the first-movers over their existing rivals and new entrants, who suffer data shortage to compete with the established ATPs.

Even though the Commission cited a stakeholder view that touches upon the interoperability challenge in the sector, ${ }^{158}$ it did not mention the legal ambiguity in applicable rules to non-personal ag-data. More importantly, it did not provide a standalone analysis regarding the switching costs in the Bayer/Monsanto decision. Instead, the Commission primarily focused on network effects and considered the first-mover advantage in the sector as a result of these effects. ${ }^{159}$ However, switching costs ${ }^{160}$ are the core reason for the first-mover advantage in the DAs compared to the relatively limited role of network effects ${ }^{161}$ that need to be considered together when assessing data-driven market power in the DAs.

Beyond the explained legal and technical barriers that prevent free data flow, there are additional factors that potentially exacerbate the impacts of data-driven switching costs in the sector. The following sections will provide an in-depth discussion about them.

would also mitigate farmers' switching costs beyond interoperability of various services. If there are data standards and interoperable infrastructures, then farmers can also change their seeding prescription services company or soil analysis company later on by keeping their previous data sets usable.

156 Kritikos, n. 107, pp. 1 and 39; See also, Ashley Ellixson and Terry Griffin, 'Farm Data: Ownership and Protections' (2017) AREC Fact Sheet | FS-1055, p. 7; See at Jeremy de Beer, 'Ownership of Open Data: Governance Options for Agriculture and Nutrition' (2016) Global Open Data - GODAN Papers, p. 14.

157 Sykuta, n. 3, pp. 68-69.

158 See Bayer/Monsanto, n. 8, para 2842, table 170.

159 See ibid., paras 2843-2844.

160 Deriving from legal and technical barriers that result in the data-driven lock-in problem in the sector, as discussed above.

161 That will be discussed in detail in Section 3.3.2.9. 


\subsubsection{Importance of historical farm data}

Historical farm data is essential for ATPs not only to develop their algorithms/ tools but also to provide tailor-made competitive services for the targeted farms. ${ }^{162}$ The Commission mentioned this briefly, but concentrated on the first aspect. ${ }^{163}$ However, the importance of historical data sets is not limited to training algorithms. Historical farm data sets are also needed to generate effective agronomic predictions based on retroactive patterns. ${ }^{164}$ Therefore, even the rivals, which have already advanced data processing tools or wide proprietary/ complementary data sets, might not be able to compete with first-mover ATPs, which exclusively control historical farm data, once farmers are locked-in due to these data sets. For this reason, accessing historical data is crucial for new entrants and existing market players, and this particularity of the sector should be taken into account specifically as a factor that further deteriorates the explained data related lock-in concerns in the DAs.

In some cases, the so-called velocity of data might also be the critical element when analyzing data's role on market power whereas in other instances, having historical data sets might be the core asset to give rise to market power. Sometimes both of them may have equal importance. It should be noted that the importance of historical data is valid predominantly for 'farm data' and possibly 'proprietary data' sets of ATPs while real-time access to accurate complementary data, such as weather data or satellite data, might be more relevant as this component of ag-data inherently requires velocity.

In this regard, the data-driven market power analysis should be conducted by separating different data types required for the particular Digital Agriculture service and also identifying the importance of each especially by taking into account the relevance of the velocity of data or historical data sets to generate the competitive services in the relevant market. In the case of Bayer/Monsanto decision, the Commission successfully separated the related data sets in the descriptive section, ${ }^{165}$ but did not provide the suggested standalone discussion especially regarding the importance of historical farm data sets.

\footnotetext{
162 See at Sykuta, n. 3, p. 69; See also Sundmaeker et al., n. 4, p. 143.

163 See Bayer/Monsanto, n. 8, para 2570. See also general statements regarding data accumulation and its importance for improving the tools, i.e. positive feedback loops at paras 2830-2846.

164 Keith H. Coble, et al., 'Big Data in Agriculture: A Challenge for the Future' (2018) 40 Applied Economic Perspectives and Policy, pp. 87 and 91.

165 See Bayer/Monsanto, n. 8, para 2453.
} 


\subsubsection{Importance of data combination}

Interrelated to the statements above, the combination of different types of data can be precious for providing accurate Digital Agriculture services, ${ }^{166}$ and the Commission successfully explored this sector characteristic and the special need for data combination in the data-driven prescription services. ${ }^{167}$ Particularly, it linked the possibility of creating a competitive advantage with unique access to proprietary and third-party data sets ${ }^{168}$ and considered the importance of field testing and proprietary data sets as the necessary element to provide services in the markets for agronomic prescription services. ${ }^{169}$ Also, locked-in farm data sets of the existing customers have an influential role in entry barriers in the sector, as explained above. It might even be argued that the farm data sets are the most critical part of the agricultural prescriptions because they make the services tailor-made that is the most distinctive characteristic of the DAs. Therefore, the importance of each data component (especially, the role of farm data on the required combination) should be determined and assessed in detail in an optimal market power test in the DAs.

\subsubsection{Costs of 'Smart Farming' and scarcity of alternative data collection sources}

Adoption of the so-called 'Smart Farming' is strictly related to costly equipment and machinery investments in addition to the role of subsidies and tax benefits as financial incentives. ${ }^{170}$ For this reason, relatively developed farms might be more expected to switch to data-driven farming from traditional farming. For even these farms, there are still doubts whether these benefits can quickly compensate for the required investments ${ }^{171}$ despite the significant benefits of Digital Agriculture. ${ }^{172}$ Additionally, when farmers need to expand 'Smart Farming' practices towards their second and/or third lands or barns, they have to invest nearly the same amount once again for setting the data

166 Sundmaeker et al., n. 4, pp. 143-144; Copa-Cogeca, n. 150, pp. 2 and 5.

167 Bayer/Monsanto, n. 8, para 2733.

168 Ibid., para 2728.

169 Ibid., para 2805.

170 Esmeijer et al., n. 136, p. 13; see also ibid., para 2838 for the importance of the high adoption rate in the sector.

171 See for example at Iria Soto et al., 'The Contribution of Precision Agriculture Technologies to Farm Productivity and the Mitigation of Greenhouse Gas Emissions in the EU' (Joint Research Center, 2019), pp. 21-22.

172 See the remarkable differences between conventional production and data-driven production in field trials, for instance, in terms of crop yield, soil fertility loss, quality of crops, input consumption percentages at 'Internet of Food and Farm 2020' (iof2020eu, 2020) https://www.iof2020.eu/communication-materials/iof2020-booklet -2019-highres.pdf accessed 5 January 2021. 
collection infrastructure as well as service fees of ATPs as much as the first investment. Therefore, it can be argued that ATPs' data collection capacity is naturally interconnected with farmers' intentions to switch to 'Smart Farming', which is strictly related to the mentioned fixed and marginal investment costs.

In this environment, farmers are at the center of the data collection stage in the fields, ${ }^{173}$ and Digital Agriculture services are up to 'farmers' ability to automatically upload their field data'. ${ }^{174}$ This distance from fields decreases ATPs' control on the data collection stage. The mentioned distance between ATPs and data collection in the fields is eliminated to a large extent by IoT devices, which collect data and automatically send it to databases of ATPs, but the help of IoT facilities to eliminate the physical distance sometimes has limitations due to a farm's distance to required infrastructure. For instance, due to internet connection problems, data transfer from field to ATPs might be interrupted. ${ }^{175}$ This can be extended to electricity, defect of the sensors, and other essential infrastructural and technical problems. All these challenges have to be overcome by farmers. In this regard, it can be put forward that ATPs' distance to data collection stage is also related to: (1) farms' distance to essential infrastructures, and connected to this; (2) their heavy responsibility regarding (a) setting the IoT infrastructure in farms, (b) keeping the data collection tools in working condition, and (c) solving problems regarding the infrastructure. All these costs significantly influence data collection alternatives, and in turn, the value of data accumulation (especially, locked-in farm data sets) in the hands of first-movers in the sector. Therefore, understanding the value of already collected farm data is important for data-driven market power assessment beyond the direct role of costly infrastructures when changing ATPs due to the technical incompatibility of systems, as explained above.

\subsubsection{Business model and distance to data effect}

The reason for farmers' data collection costs is also related to the business model of the DAs. Although the Commission stated in the Bayer/Monsanto decision 'business models in digital agriculture are not stable', ${ }^{176}$ the critical

173 EU Code of Conduct, n. 127; as well as responsible for the quality and credibility of data. See at Copa-Cogeca, n. 150, p. 2.

174 Bayer/Monsanto, n. 8, para 2688. However, the Commission did not focus on this that much.

175 See more at Brian E. Whitacre, Tyler B. Mark, and Terry W. Griffin, 'How Connected Are Our Farms?' (2014) 29 (3) The Magazine of Food, Farm, and Resource Issues 1; and Zerina Kapetanovic, 'Farmbeats: Empowering Farmers with Low-Cost Digital Agriculture Solutions' https://www.microsoft.com/en-us/research/video/ farmbeats-empowering-farmers-with-low-cost-digital-agriculture-solutions/?OCID= msr_video_farmbeats_facsum_tw\#!related_info accessed 5 January 2021.

$1 \overline{7}$ Bayer/Monsanto, n. 8, para 2991. 
Table $3.1 \quad$ Business model of the Digital Agriculture sector

\begin{tabular}{|c|c|c|c|c|}
\hline $\begin{array}{l}\text { Services for Users } \\
\text { or Customers }\end{array}$ & $\begin{array}{l}\text { Data Collection } \\
\text { Awareness and } \\
\text { Role of Data in } \\
\text { Services }\end{array}$ & $\begin{array}{l}\text { Main Income of the } \\
\text { Businesses }\end{array}$ & $\begin{array}{l}\text { Primary } \\
\text { Purpose } \\
\text { of Data } \\
\text { Collection }\end{array}$ & $\begin{array}{l}\text { Secondary } \\
\text { Purpose of Data } \\
\text { Collection }\end{array}$ \\
\hline $\begin{array}{l}\text { Data-driven } \\
\text { digitally enabled } \\
\text { agronomic / } \\
\text { solutions / } \\
\text { prescriptions/ } \\
\text { observation } \\
\text { services }\end{array}$ & $\begin{array}{l}\text { Data collection } \\
\text { is up to farmers' } \\
\text { explicit intention, } \\
\text { investment and } \\
\text { practice } \\
\text { Data is the core } \\
\text { input for services }\end{array}$ & $\begin{array}{l}\text { Via subscription } \\
\text { fees for data-driven } \\
\text { agronomic services. } \\
\text { Business income } \\
\text { mainly depends on } \\
\text { the size of acres } \\
\text { and number of } \\
\text { customers }^{\text {a }}\end{array}$ & $\begin{array}{l}\text { To provide } \\
\text { tailor-made } \\
\text { agronomic } \\
\text { services for } \\
\text { customers } \\
\text { (farmers) }\end{array}$ & $\begin{array}{l}\text { To train } \\
\text { algorithms, fix } \\
\text { errors, enhance } \\
\text { services } \\
\text { Network effects } \\
\text { enabled by the } \\
\text { scale and scope of } \\
\text { data }^{\text {b }}\end{array}$ \\
\hline
\end{tabular}

Notes: ${ }^{\mathrm{a}}$ See Section 3.3.2.8; ${ }^{\mathrm{b}}$ See Section 3.3.2.9.

information to identify the business model of the DAs might be that Digital Agriculture services (including agronomic prescription services) are not free of charge, ${ }^{177}$ and the service fees consist of the primary business income of ATPs. ${ }^{178}$

Additionally, it can be observed that data is not an externality of service usage. Instead, farm data is the center of the agronomic prescription services as an irreplaceable input in such a way that farmers intentionally set the data collection infrastructures to extract and send data to ATPs in order to get tailor-made data-driven solutions from ATPs by paying subscription fees. ${ }^{179}$

This chapter argues that there is a novel relationship between farmers and ATPs due to the special value of farm data. On the one hand, there is a distance between farmers and already collected farm data sets due to legal and technical barriers, as discussed above. Farmers do not have any explicit legal or practical position to control data after the data collection stage (farmers' distance to data). On the other hand, ATPs have limited discretion on farmers' costly data collection investments, and thus, their data collection capacity is interrelated with farmers' technological transformation. This cross-relation cannot be easily overcome by ATPs alone. Thus, their distance from data collection stage (ATPs' distance to data) increases the value of farm data sets for ATPs, which

177 Joddy L. Ferris, 'Data Privacy and Protection in the Agriculture Industry: Is Federal Regulation Necessary?' (2017) 18 Minn. J. L. Sci. and Tech. 1, p. 314.

178 See generally at Sundmaeker, n. 4; See Bayer's business model at Bayer/ Monsanto, n. 8, para 2490 and 2547; See also the FieldView as an example at 'Pricing' (FieldView) https://climate.com/pricing accessed 5 January 2021.

179 Notifying Party also stated the ATPs' dependency on the farm data collection process operated by farmers. See at Bayer/Monsanto, n. 8, para 2688. 
in turn, exacerbates the effects of the data related lock-in problem from the perspective of entry barriers for new entrants and expansion barriers for existing rivals as a result of the problem of switching costs for farmers.

ATPs' distance to data due to farmers' centrality in data collection and its costs for farmers might bring about the question of whether this can constitute a significant countervailing bargaining power for farmers. However, this chapter is cautious about this possibility because farmers have equal or even (arguably) more incentive to collect data and receive Digital Agriculture services to reach more efficient and productive farming solutions. In this regard, farmers might not effectively use the data collection argument to bargain with ATPs because farmers demand technology services from ATPs by knowing that they will invest in data collection infrastructure and pay for Digital Agriculture services unless they have large operations with considerable data potential that can particularly draw ATPs' attention to consider exceptional pre-contractual bargaining processes. ${ }^{180}$ Moreover, large operations of farmers might not directly affect ATPs' claim on collected data sets since companies have other options to bargain with farmers such as offering discounts for the given services. Therefore, it can be stated that ATPs' distance to data does not necessarily increase (especially relatively small) farmers' bargaining power as they do not have any level playing field to change standard terms and conditions of the Digital Agriculture services. Instead, this makes farm data highly valuable for ATPs and increases the anticompetitive potential of already aggregated data sets in the hands of limited ATPs. Moreover, ATPs' distance to data does not mean that farmers have control over already collected data sets as already explained above in the scope of farmers' lack of control after data collection stage, i.e. farmers' distance to data.

To mitigate farmers' distance to data problem, cooperatives can come to mind as an effective mechanism that may increase farmers' bargaining power. As already discussed in the case law, ${ }^{181}$ farmers' cooperatives can purchase agricultural inputs wholesale in order to benefit from discounts, and they can impose restrictive rules on their members 'to forbid them to participate in other forms of organized cooperation which are in direct competition with it'. ${ }^{182}$ Therefore, one can consider whether a similar form of organization could be a solution to ease farmers' distance to data after the data collection stage by entering into agreements with ATPs as a powerful entity. This could be a promising attempt to increase countervailing buyer power of farmers

180 However, in the scope of this research, no such situation has been encountered in the literature or sector investigation.

181 See at Gøttrup-Klime.a. GrovvareforeningervDanskLandbrugs Grovvareselskab AmbA, ECLI:EU:C:1994:413.

182 Ibid., para 45. 
vis-à-vis ATPs, ${ }^{183}$ but this chapter is also skeptical about the possible success of such an endeavor. As the nature of the DAs is based on tailor-made solutions/suggestions/services to individual farms, it might be challenging to organize a collective agreement. Additionally, as explained in the above paragraph, ATPs might offer other alternatives such as reduced prices instead of renouncing their exclusive de facto control on collected data sets. More importantly, this type of collective agreements might constitute another set of switching costs for individual farmers when they desire to change the service providers during the process due to potentially restrictive rules of these cooperations. However, there are initiatives to create intermediary data pooling cooperatives to store collected farm data and open-up these data sets to ATPs according to farmers' requests later on. ${ }^{184}$ These initiatives might be useful to mitigate concerns on switching costs, but, still, established first-movers do not have any explicit incentive to let farmers change the existing practice in the sector. This makes the distance to data effect (especially from the farmers' side) more concerning as the market forces might not be able to correct the failure easily without external intervention. Nonetheless, the potential of the explained pooling intermediary initiatives might still be valid for new 'digital farmers', as they can choose ATPs accordingly.

\subsubsection{Lack of data substitutability}

The level of data substitutability has been emphasized by various reports as an indicator of data-driven market power, i.e. if competitors cannot easily access the same required data, then substitutability level is low, and there is a higher level of concern and vice versa. ${ }^{185}$ Therefore, it is stated that data sets of the undertaking(s) under investigation and available substitutable data for their rivals should be taken into account when assessing market power. ${ }^{186}$

This issue has long been discussed by the Commission in online platforms cases, but with a different perspective, as a relieving factor for data combinations via mergers such as in Google/DoubleClick, ${ }^{187}$ Telefónica UK/

183 Even though such an initiative has not been encountered in the scope of this research.

184 See, for instance, 'JoinData - The Future of Smart Farming' (Join-data.nl, 2019) https://www.join-data.nl/en accessed 5 January 2021; see more about the platform at 'Data Sharing in the Agricultural Sector | Support Centre for Data Sharing' (Eudatasharing.eu, 2019) https://eudatasharing.eu/examples/data-sharing-agricultural -sector accessed 5 January 2021.

185 EU Report, n. 41, p. 49; Franko-German Report, n. 71, pp. 44-47.

186 Ibid

187 Case No. COMP/M.4731 - Google/ DoubleClick, Commission Decision (11 March 2008), paras 269-272 and 365-366. 
Vodafone UK/Everything Everywhere/JV, ${ }^{188}$ Facebook/WhatsApp ${ }^{189}$ because of the availability of substitutable data for competitors. For instance, it is stated in the Facebook/WhatsApp case that 'there will continue to be a large amount of Internet user data that are valuable for advertising purposes and that are not within Facebook's exclusive control'. ${ }^{190}$ The 'exclusive control' emphasis was also placed in the Microsoft/LinkedIn merger. ${ }^{191}$ It can be observed that the Commission is lenient about the data concentrations unless they are exclusively controlled by the merging entities.

Due to the sector-specific conditions in the DAs, the substitutability of data argument, which is repeated in online platforms cases, should be reconsidered cautiously in possible DAs cases. It can be put forward that substitutability level of farm data sets can be very low in the DAs due to inter alia the data-driven lock-ins, high data collection costs and scarcity of data collection alternatives which are encapsulated by the notion of distance to data effect (from both ATPs' and farmers sides) in this chapter as explained above. Apart from farm data, a substitutability assessment might also be meaningful for proprietary data sets (data about the performance of agricultural inputs) as they are naturally exclusively produced and controlled by input producers. Therefore, there could be a test to assess the substitutability level of each data set under investigation. ${ }^{192}$

A substitutability assessment is not only related to the same data sets, but also relevant for economies of scope enabled by data. The combination of different data sets (including farm data, proprietary data and complementary data) is one of the prominent characteristics of the DAs. ${ }^{193}$ In this regard, it can be argued that substitutability of required data variety, i.e. whether providing a competitive service with slightly different combinations might also be pos-

188 Case No. COMP/M.6314 - Telefónica UK/Vodafone UK/Everything Everywherel $J V$, Commission Decision (4 September 2012), para 543.

189 Facebook/WhatsApp, n. 98, paras 188-189.

190 Ibid., para 189.

191 Case No. COMP/M.8124- Microsoft/LinkedIn, Commission Decision (6 December 2016), para 180.

192 Beyond the market power assessment, the Commission could consider imposing data portability remedy for locked-in farm data sets in order to mitigate concerns regarding high entry barriers or data access obligations for proprietary data sets in favor of new entrants or existing rivals, especially when such data is the pre-requisite for doing business in certain markets.

193 Bayer/Monsanto, n. 8, para 2733. As this was determined by the Commission, it can be acknowledged that the Commission considered the issue (importance of data combination) in the decision properly even though it over-focused on proprietary data advantage of integrated giants. 
sible or not, should also be one of the elements in data-driven market power test in the DAs.

In the Bayer/Monsanto decision, the Notifying Party claimed that there was no unique access for proprietary or third-party data, but the Commission did not directly respond to this and provided a general statement that merging parties have special capabilities that put them in an advantageous position compared to rivals. ${ }^{194}$ Although the Commission mentioned the importance of access to ag-data for entering into a market in the $\mathrm{DAs}^{195}$ or discussed the advantage to offer, improve or develop new services with superior access to proprietary and complementary data sets, ${ }^{196}$ the substitutability levels of related data sets were not discussed at all in the decision. More importantly, the role of farm data on market power was underestimated to a large extent. In this respect, this silence in the Bayer/Monsanto decision regarding the substitutability of data sets is worth further investigation to identify whether it means a diversion from the older precedents based on online platforms cases by realizing the sector conditions, or whether it was entirely ignored in the case by considering the remedy, The BASF Divestment Package ${ }^{197}$ that would keep Digital Agriculture operations of the merging parties separate anyway. Regardless of the reason for this silence, it should be noted that market power assessments in the sector should not neglect the substitutability levels of related data sets (especially the farm data component) in light of the particular markets' conditions.

\subsubsection{Practical rivalrousness of farm data}

Just like other data types, farm data is non-rivalrous from a technical perspective because multiple players can use identical farm data at the same time. However, it can be argued that the profitability of data collected from farms might be rivalrous in practice due to the novel business model of the DAs. Farm data cannot be used profitably by more than one company at the same time in the same market for agronomic prescription services because income comes from farmers' subscription fees for the tailor-made agronomic services, ${ }^{198}$ not data-driven targeted advertisement, for instance. Therefore, replicated data would not be directly profitable by any other company unless the farmer replaces the existing service provider, and starts paying the fees. The only benefit to access farm data from non-contractual farms might be training the algorithms or providing shadow services to compete with existing ATPs by convincing farmers with more accurate and better services than the

\footnotetext{
194 Ibid., para 2728.

195 By referring Monsanto's considerations on the matter. See at ibid., para 2452.

196 Ibid., paras 2715-2728.

197 Ibid., para 3046 and subsequent paras.

198 See Section 3.3.2.5 above.
} 
existing provider. In this regard, due to the practical rivalrousness, farm data might only be indirectly profitable for rivals in the same market, but technically non-rivalrous data can still be valuable to use in connected markets that require the same farm data.

There might be an exception here for the non-rival use of 'farm data' by rivals at the same time. For instance, there are field information services like AcreValue that process various data including soil type and crop yields, and other relevant historical data to help farmers choose a correct field to buy or rent. ${ }^{199}$ In this market, farm data can be used by all the rival companies at the same time to provide the best service to customers because of the peculiarity of this particular service. Similarly, replicability and non-rivalrousness discussion might be more meaningful for complementary or proprietary data sets because more than one company can use them to make a profit at the same time in the same market as all the ATPs need to complement these data sets with the farm-specific data of their customers.

In this regard, it is important to note that the replicability or non-rivalrousness of data should be discussed carefully in market power analysis of the DAs cases. The Commission should take into account the type of the aggregated data and the particular business model of the relevant market in the broader DAs and should be highly cautious when implementing its precedents from online platforms cases based on the argument of abundance, replicability or non-rivalrousness of data, especially when it comes to farm data.

\subsubsection{Economies of scale in providing agronomic prescription services}

The Commission stated in the Bayer/Monsanto decision that the economies of scale is a 'key element to ensure the competitiveness and viability. Therefore, the development of services for broad acre crops is more attractive' compared to prescriptions for smaller-scale farming such as fruits and vegetables. ${ }^{200} \mathrm{In}$ this regard, it can be inferred that the data-driven competitive advantages of ATPs might be different in different prescription markets for different crop groupings according to the scale of the farming activities. In the crop groups that are grown in smaller-scale fields, a data-unit might be more important (especially for training algorithms) because of the limited total acres as the potential data collection sources due to the nature of the particular agricultural production. If the related market is dominated by few players, this might result in higher entry barriers for the new entrants who suffer from data shortage to

199 'Acrevalue - Granular' (Granular, 2020) https://granular.ag/acrevalue/ accessed 5 January 2021; Similar data is also used for scouting services. See Bayer/Monsanto, $\mathrm{n}$. 8 , para 2489 (3), and 2505.

200 Ibid., para 2577. 
train algorithms compared to markets that provide Digital Agriculture services for large-scale production that naturally result in more total data to feed data processing tools of market players. Furthermore, this may make comparisons of data aggregation levels between different DAs markets difficult. For instance, it may be misleading to take data aggregation levels in a large-scale market as a benchmark for a small-scale market when evaluating how concerning a data concentration is.

In this regard, the scale of the farming activities, its reflection on the data collection scale for agronomic prescription services, and the structure of the particular market under investigation should be explored in detail when assessing the role of data on market power in the DAs cases. For instance, data aggregation in the hands of limited players might be more concerning in the markets which provide services for small-scale agricultural production compared to markets that have more data potential due to the large-scale agricultural production.

\subsubsection{Positive feedback loops instead of direct network effects}

As discussed in detail above when explaining the business model and distance to data effect, farmers' primary objective to implement data collection infrastructure and to take paid tailor-made suggestions/prescriptions from ATPs is more related to making better farming decisions and increasing their productivity rather than reaching other farmers or their data directly. Therefore, an ATP having a vast network of farmers does not necessarily attract other farmers directly. In this sense, it is very difficult to argue that direct network effects are one of the main economic characteristics in the DAs. Consequently, focusing on direct network effects might be misleading in market power assessments in the DAs.

In the Bayer/Monsanto merger decision, the Commission focused on data-driven positive feedback loops even though it used 'network effects' as a broader notion that typically covers both direct and indirect network effects. The Commission considered that first-movers might have a quality advantage compared to late-comers, and thus, the users would not have any incentive to switch new services. ${ }^{201}$ It is reasonable to argue that having a large number of farmers (as customers) means having a wide variety of farm data, ${ }^{202}$ which can be used to develop algorithms and services, and thus, to attract others with high-quality services. In this sense, indirect network effects deriving from the

201 Ibid., para 2837.

202 However, it is important to note that this kind of generalization might not always be valid because sometimes limited customer farms may mean more data and subscription income for ATPs if they conduct large scale farming activities. See the suggestion for an innovative market share calculation for the DAs cases in Section 3.3.1 above. 
scale and scope of data advantage are one of the non-negligible factors when assessing entry barriers in the DAs, and the Commission did it in its decision properly.

However, in the same paragraph, the Commission considered network effects as the main reason for the first-mover advantage and entry barriers. ${ }^{203}$ This chapter opposes this consideration by virtue of two main reasons, especially from the perspective of the broader DAs. First, there is a robust first-mover advantage in the sector, but the core reason for this is more related to switching costs, as explained above. Second, presenting consumer accumulation deriving from better services as a competition problem seems a bit awkward because it is a natural consequence rather than explicit and direct harm for consumers even though this may affect the entry barriers after all. Therefore, it can be argued that constructing the theory of harm based on switching costs might be a more sound base in the DAs cases as there is a definite problem if the users are locked in the low-quality services compared to innovative and better alternatives in the market.

\subsection{CONSIDERATIONS AS TO THE BAYER/ MONSANTO DECISION AND SUGGESTIONS FOR FUTURE CASES}

Building on the in-depth discussion above, the following issues can be stated as prominent regarding the Commission's data-driven market power assessment in the Bayer/Monsanto decision and should be particularly taken into account in future market power inquiries in the sector.

First of all, the Commission did not consider market shares in its assessment as it could not reach reliable data. ${ }^{204}$ Indeed, focusing solely on market shares might be misleading to estimate the market power in the dynamic and still emerging DAs. Additionally, when considering farmers' weaker position vis-à-vis ATPs and 'take it or leave it' type of terms and conditions, countervailing buyer power might not be a meaningful competitive constraint as well. ${ }^{205}$ Therefore, the core element to investigate market power in the DAs should be based on entry barriers. However, still, innovative methods to estimate market shares might be helpful to complement entry barriers analysis, such as focusing on the number of acres for which an ATP provides services compared to the total available acres in the market. ${ }^{206}$

203 See Bayer/Monsanto, n. 8, para 2837.

204 Ibid., para 2613.

205 See Sections 3.3.1 and 3.3.2.1.

206 See more in Sections 3.3.1 and 3.3.2.8. This can be adapted according to the conditions of the market under investigation. For instance, the Commission can check the 
Regarding the assessment of the economic characteristics, the Commission over-relied on stakeholders' ideas via questionnaires and internal documents throughout the text instead of providing in-depth analytical discussions to justify its position. Apart from the method, the Commission indicated network effects as the main reason for the first-mover advantage in the sector. ${ }^{207}$ However, the core reason for the first-mover advantage mainly derives from the switching costs compared to the relatively limited role of indirect network effects stemming from positive feedback loops. ${ }^{208}$ Therefore, the Commission's overemphasis on network effects ${ }^{209}$ by neglecting to discuss switching $\operatorname{costs}^{210}$ might be problematic, and it should be revised in future investigations. ${ }^{211}$ As a more general consideration, instead of arbitrarily mentioning various economic characteristics in the analysis, a checklist, which covers all the potential characteristics, can be created to provide an overview to see which factors exist and which are absent, which reasons intensify existing factors, and to explain why the particular characteristics are chosen for market power analysis as the reasoning of the decision.

There are definite factors that should be kept in mind as they have the potential to exacerbate the role of switching costs in the sector;

- The concentration of farm data can be highly problematic due to the explained switching costs in the DAs, but the Commission underestimated this and focused on proprietary data sets in the Bayer/Monsanto decision. ${ }^{212}$ It also did not mention the cruciality of historical farm data sets for farmers when changing service providers. ${ }^{213}$ It can be argued as a general point

number of cows for which an ATP provides data-driven animal health solutions compared to the total cows being traced and served in the same market.

207 See Bayer/Monsanto, n. 8, para 2837.

208 See the overall discussion in Section 3.3.2.

209 See Bayer/Monsanto, n. 8, paras 2843-2844.

210 It did not provide a standalone discussion on the lock-in problem in the sector.

211 Especially, it may affect the remedies and their effectiveness regarding addressing competitive concerns. For instance, if it had identified the switching costs in detail, the Commission could have considered data access or data portability obligations in favor of rivals and farmers, respectively, in addition to the divestment package.

212 See Bayer/Monsanto, n. 8, paras 2715-2728. Maybe the reason for this is related to the fact that Monsanto had not yet started its operations in the EEA, and thus, did not have large farm data sets in Europe at the time of the merger. However, as the main focus of the Commission was on elimination of potential competition, Monsanto's potential farm data coverage after initiating the EEA operations in full capacity might have been discussed.

213 It only mentioned historic data sets when explaining that data aggregation is key for training/improving tools. Ibid., para 2570. Again, switching costs discussion could have been made by considering the post-operational period of Monsanto in the EEA. 
that the importance of data combination and historical farm data sets in the context of switching services should be paid attention when assessing entry barriers in the DAs while not neglecting the role of real-time access to complementary data sets (about weather or satellite images). Additionally, market power assessments in the DAs should first categorize the relevant data sets under investigation and determine their potential importance for given services. The Commission separated different data types, ${ }^{214}$ and mainly explained the importance of proprietary data sets, ${ }^{215}$ but failed to provide a detailed discussion about distinctive competitive effects of each data set and especially, neglected the farm data analysis in the relevant market.

- Adopting Smart Farming is a costly transformation for farmers due to high fixed and incremental costs in addition to farmers' maintenance responsibilities and subscription fees of digital services. ${ }^{216}$ Thus, farmers become at the center of the data collection stage. They need tailor-made prescriptions/ suggestions/solutions, and ATPs need farm data not only to make a profit but also to develop their algorithms and services. This cross-relationship requires a novel way of thinking when considering market power in the DAs cases, which was absent in the Bayer Monsanto decision. As this is another factor that can affect switching costs assessments in the DAs, entry barriers investigations should take into account the explained distance to data effect, i.e., whether the level of ATPs' control on data collection stages is high or low, and to what extent farmers control the already collected data sets (the intensity of data-driven lock-in situations).

- Data-driven lock-ins due to legal and technical problems, data collection costs and scarcity of data collection sources influence the substitutability of data in the sector. However, the Commission kept silent on the substitutability of ag-data, unlike its previous decisions in online platforms cases. ${ }^{217}$ This could mean a diversion from the older precedents by considering the distinctive conditions in the sector, or the Commission might have just neglected this discussion in this case. Regardless of the reason for this silence, it should be noted that the substitutability levels of related ag-data sets under investigation should be one of the essential elements of the market power assessments in the sector.

\footnotetext{
214 Ibid., para 2453.

215 Ibid., para 2733; and somehow complementary data sets. See at para 2728.

216 See Sections 3.3.2.4 and 3.3.2.5.

217 The Commission has been lenient about data concentrations in online platforms cases by considering the abundance of available/substitutable data for rivals. See Section 3.3.2.6.
} 
- Connected to the substitutability discussion, it is also essential to understand the practical rivalrousness of farm data from the perspective of directly making a profit out of it. Farm data from non-contractual farms might not be used to generate direct profit by ATPs unless they convince the farmers to switch their existing service providers, excluding some exceptional situations in the DAs. ${ }^{218}$ In this regard, farm data can be practically rivalrous, unlike proprietary and complementary data sets that can be used by various ATPs in the same market in a directly profitable manner. As the Commission did not put emphasis on the business model of the sector and the role of farm data on market power in the Bayer/Monsanto decision, it did not identify this issue as well. However, it can be argued that the suggested substitutability of data analysis should also cover the potential practical rivalrousness of farm data sets in each case in accordance with the particular business model and other features of the relevant market under investigation.

- The economies of scale in providing agronomic prescription services are rightfully determined and considered in the Bayer/Monsanto decision, but the relationship between the importance of a data-unit and the risks of dominance in different DAs markets that provide services to different scales of agricultural production is absent in the Commission's analysis. In this regard, it can be argued that data aggregation might be more concerning in Digital Agriculture markets for small-scale agricultural production where the total scale of data would also be limited, compared to the markets that provide services for large-scale agricultural production where the total data would naturally be more. Therefore, the scale of farming activities, which are served under a particular DAs market, should also be determined during the substitutability/replicability of data assessment as this is relevant for the market power of ATPs under investigation, especially from the perspective of training the algorithms.

\subsection{CONCLUSION}

This study has aimed to investigate the role of agricultural data on market power in the DAs, and, in particular, to critically analyze the Bayer/Monsanto decision in light of the distinctive features of the sector in order to identify indispensable elements of an optimal market power test for the DAs.

In the scope of this investigation, it can be concluded that the core focus when assessing market power in the sector should be on entry barriers in light

218 See more in Section 3.3.2.7. 
of an in-depth economic characteristics analysis. ${ }^{219}$ The main novelties in this regard derive from very high legal and technical barriers preventing free data flow, the vitality of data combination, the special importance of historical farm data sets, significant data collection costs for farmers, cruciality of data collection for ATPs, and lack of data substitutability, especially for farm data sets. ${ }^{220}$ These characteristics have a collective potential to significantly give rise to the market power of those who hold data exclusively. Interrelated to this, there is a sector-specific cross-dependency between farmers and ATPs that has been explained as the distance to data effect both from ATPs'and farmers' sides. ${ }^{221}$ Due to the distinctive nature of the sector, ATPs have limited control over data collection stages, which makes farm data highly valuable for them. At the same time, farmers lack control after the collection stage due to legal ambiguity about the applicable (or existence of any) legal framework on data rights and interoperability problems as technical barriers to transfer data when farmers decide to change existing service providers. In such an environment, switching from one ATP to another is very costly and sometimes nearly impossible for farmers due to very harsh lock-in situations, and, thus, there is a solid first-mover advantage for ATPs who have already reached a certain amount of users. Although switching costs are the main reason for entry barriers and there are no direct network effects in the sector ${ }^{222}$ positive feedback loops as indirect network effects also contribute to these already high entry barriers in the emerging DAs.

As the DAs covers a wide variety of data-driven services, each can be considered as different markets. Therefore, the roles of farm data, proprietary data and complementary data on the market power of service providers might vary according to the specific conditions of each particular market. For instance, field biomass measurement services might be predominantly dependent on satellite data ${ }^{223}$ while irrigation products or spraying prescription services might primarily need climate data and farm data beyond satellite data ${ }^{224}$ or some services such as farm management products might solely use data pro-

219 In addition to the helpful potential of the innovative methods such as focusing on the ratio of acres that an ATP provides services for compared to the total acres in a market. See Section 3.3.1.

${ }_{220}$ They are mostly neglected in the Bayer/Monsanto decision except for the vitality of data combination. See more in Section 3.3.2 in general and Section 3.4 above.

221 See Section 3.3.2.5.

222 Because the main aim of farmers is receiving tailor-made agronomic services, not reaching other farmers or their data directly. See Sections 3.3.2.5 and 3.3.2.9.

223 See, for instance, Monsanto's Field Health Imagery product at Bayer/Monsanto, n. 8 , para 2505 .

${ }_{224}$ See, for example, AquaTEK at ibid., para 2508; and Field Manager at ibid., para 2538. 
duced in the target farms. ${ }^{225}$ In this regard, understanding the particular role of each data set in the related market under investigation is of crucial importance. Therefore, all cases should be investigated specifically according to their facts, conditions, and particular business model of each market in addition to the sector-wide relevant factors discussed above when assessing market power in the DAs cases.

Building on the substantial discussion above, it can be put forward that optimal market power test should include the following steps: (1) determination of required data types for the given service in the market under investigation, and their legal status; (2) assessment of each data set's distinctive importance for generating the related agronomic service/solution; (3) analysis of the substitutability levels of each data set by considering the applicable (or existence of any) legal regime as well as the distance to data effect (from both farmers' and ATPs' sides), ${ }^{226}$ especially for farm data component; ${ }^{227}$ and (4) a comprehensive discussion about how concerning the data concentration as a result of the merger would be and the reasons for the related concerns in light of an in-depth economic characteristics and business model analysis. ${ }^{228}$ Thus, the formulation of remedies would become more effective and targeted to the specific reasons for the related concerns in the relevant market.

With regards to the suggestions for future research, there is a need for particular attention to switching costs deriving from data lock-ins that create very high entry barriers in the sector. Therefore, future research can analyze the adequacy of existing legal frameworks to address the lock-in problem in the DAs. In such harsh sector conditions, it might even be discussed whether regulatory intervention is necessary beyond the competition law enforcement in order to eradicate at least the legal barriers (preferably mitigate technical barriers as well) to facilitate free data flow with a cost-efficient and fair regulatory framework without hindering data-driven innovation in the sector.

${ }^{225}$ For instance, VitalFields provides record-keeping services to its customer farms. See at ibid., para 2509.

226 I.e., assessing the intensity of data-driven lock-in situations and the level of ATPs' control on data-collection stages, and thus, value of farm data accumulation for ATPs. See Sections 3.3.2.5 and 3.3.2.6.

227 The Commission determined the data types, but neglected the legal status and substitutability levels of related data sets in its analysis. It identified the proprietary data sets' importance in detail when providing services, but underestimated the distinctive role of the farm data component in the Bayer/Monsanto decision. See the details of these and other criticisms in Section 3.4 above.

228 A checklist can be created for a more systematic analysis. 